Научная статья

УДК 332.1

DOI: $10.18101 / 2304-4446-2021-2-90-95$

\title{
РЫНОК ЖИЛОЙ НЕДВИЖИМОСТИ \\ В ДАЛЬНЕВОСТОЧНОМ ФЕДЕРАЛЬНОМ ОКРУГЕ: ТЕНДЕНЦИИ И ПЕРСПЕКТИВЫ
}

\author{
(c) Цыренов Даши Дашанимаевич \\ dashi555@mail.ru \\ (C) Жапова Диана Олеговна \\ обучающийся \\ zhapovadiana@gmail.com \\ (C) Цыденов Майдари Баторович \\ обучающийся \\ tmaidari@mail.ru
}

Бурятский государственный университет имени Доржи Банзарова Россия, 670000, г. Улан-Удэ, ул. Смолина, 24a

\begin{abstract}
Аннотация. Научная статья посвящена исследовательскому анализу основных тенденций и перспектив развития рынка жилой недвижимости в Дальневосточном федеральном округе (ДВФО). Актуальность исследования обусловлена сразу несколькими факторами: во-первых, тенденцией увеличения объема рынка жилой недвижимости в целом по Российской Федерации, что связано с социально-экономическим развитием государства; во-вторых, кризисом пандемии коронавирусной инфекции Covid-19, изза чего многие процессы развития рынка жилой недвижимости сталкиваются с рядом ограничивающих факторов. В рамках статьи рассмотрены особенности развития рынка жилой недвижимости в ДВФО. Проанализированы основные тенденции развития рынка жилой недвижимости в ДВФО. Выделены факторы, которые способствуют его развитию или, наоборот, создают барьеры и препятствия. Рассмотрены основные перспективы дальнейшего развития рынка жилой недвижимости в ДВФО. Нами установлено, что основными тенденциями развития рынка жилой недвижимости в ДВФО выступают увеличение масштабов ипотечного жилищного кредитования и рост цен. Такие характеристики означают увеличение рыночной капитализации жилой недвижимости и повышение совокупного спроса и предложения.

Ключевые слова: рынок недвижимости, рынок жилой недвижимости, жилая недвижимость, ипотечное кредитование, жилищное ипотечное кредитование, ипотека, жилье, Дальневосточный федеральный округ, ДВФО, рынок жилья
\end{abstract}

\section{Для цитирования}

Цыренов Д. Д., Жапова Д. О., Цыденов М. Б. Рынок жилой недвижимости в Дальневосточном федеральном округе: тенденции и перспективы // Вестник Бурятского государственного университета. Экономика и менеджмент. 2021. № 2. С. 90-95.

Современный этап развития национальной экономики Российской Федерации требует сформированного рынка коммерческой и жилой недвижимости, позво- 
Д. Д. Цыренов, Д. О. Жапова, М. Б. Цыленов. Рынок жилой недвижимости в Дальневосточном федеральном округе: тенденции и перспективы

ляющего удовлетворять потребности субъектов хозяйствующей деятельности и населения [3].

Под коммерческой недвижимостью стоит подразумевать объекты недвижимости, использование которых происходит в рамках достижения коммерческих целей субъектов. Под жилой недвижимостью стоит подразумевать объекты недвижимости, использование которых происходит в рамках удовлетворения потребностей, связанных с необходимостью выбора места жилья [5].

Именно рынок жилой недвижимости играет важную роль при формировании рынка всей недвижимости Российской Федерации. Это обусловлено как экономическими факторами, так и социальной ролью, поскольку жилье - обязательный атрибут жизни семей, обеспечивающий их благополучие [6].

Объекты жилой недвижимости можно классифицировать на следующие категории: квартиры; комнаты; дачные дома; загородные дома; коттеджи; таунхаусы; апартаменты в отелях.

Актуальность научного исследования тематики «рынок жилой недвижимости в ДВФО» обусловлена сразу несколькими факторами:

- во-первых, тенденцией увеличения объема рынка жилой недвижимости в целом по Российской Федерации, что связано с социально-экономическим развитием государства;

- во-вторых, кризисом пандемии коронавирусной инфекции Covid-19, из-за чего многие процессы развития рынка жилой недвижимости сталкиваются с рядом ограничивающих факторов.

По этой причине целью научной статьи выступает исследовательский анализ основных тенденций и перспектив развития рынка жилой недвижимости в Дальневосточном федеральном округе (ДВФО).

Первой тенденцией развития рынка жилой недвижимости в ДВФО выступает рост цен, который выражается в стоимости одного квадратного метра жилья.

Так, в 2016 г. стоимость одного квадратного метра первичного жилья составляла 66430 р., в 2017 г. - 67191 р., а в 2018 г. — 71702 р. При анализе стоимости жилья на вторичном рынке формируется аналогичная тенденция: в 2016 г. 69301 р., 2017 г. — 67411 р., 2018 г. — 70254 p. [1].

Следующей тенденцией развития рынка жилой недвижимости в ДВФО выступает увеличение уровня доступа семей к продуктам банковского ипотечного кредитования, что очень важно (рисунок 1).

С 2012 по 2019 г. доступность ипотеки для населения России выросла с 29 до $45 \%$. Это отражается в том, что объем ипотечного кредитования рынка жилья увеличивается с каждым годом.

По состоянию за второй квартал 2020 г. сделок в сумме 90 млрд р. на рынке первичного жилья было проведено с помощью ипотечного кредитования, и лишь 32 млрд p. - собственных средств. На рынке вторичного жилья сделок в сумме 203 млрд р. проведено с помощью ипотеки, а 187 млрд р. - собственных средств ${ }^{1}$.

Стоит отметить, что тенденции роста цен и ипотечного кредитования в Дальневосточном федеральном округе РФ под угрозой из-за факторов, которые свя-

1 Итоги развития рынков ипотеки. URL: https://дом.pф/upload/iblock/e8b/e8b089e88 ad8d89e195114ac8f554d7b.pdf (дата обращения: 29.03.2021). Текст: электронный. 
заны с рыночной конъюнктурой в отечественной практике, где наблюдается высокая волатильность из-за динамичности внешней среды [2].

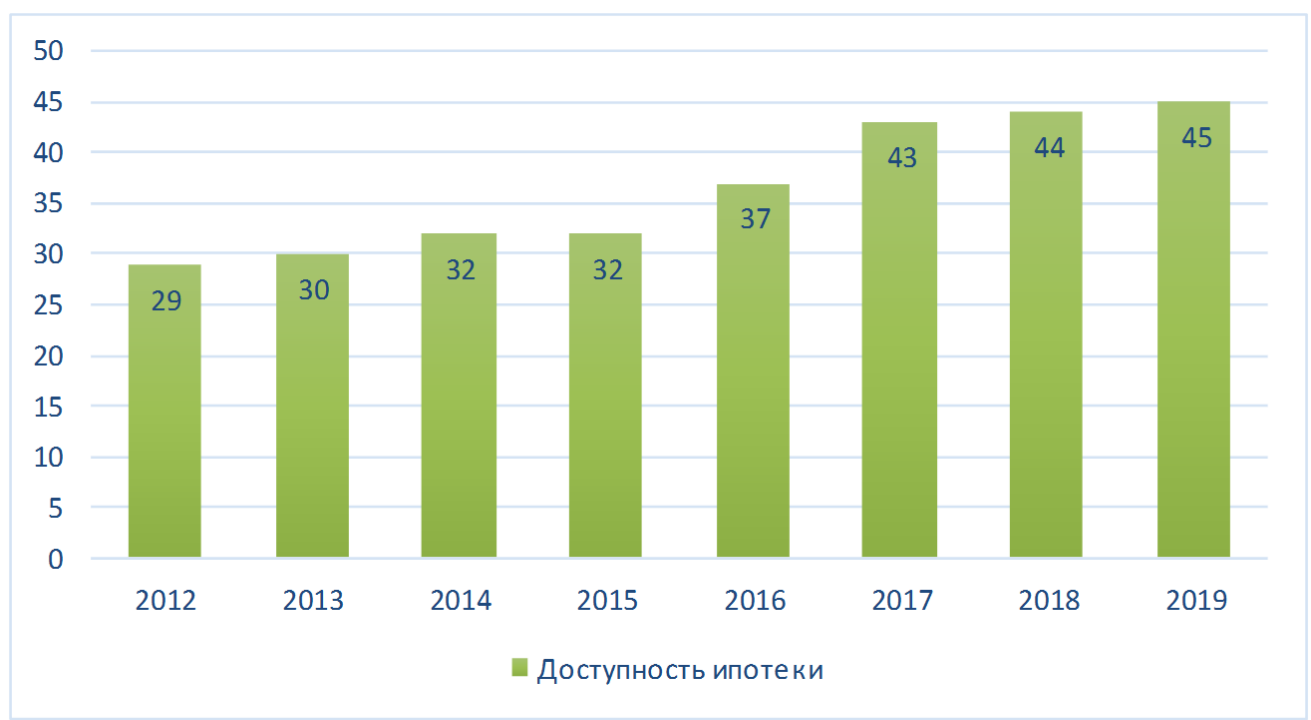

Рис. 1. Доступность ипотеки для населения России за период 2012-2019 гг., в \%

Особую степень влияния ощущает рынок недвижимости в период 20202021 гг., когда на оценку стоимости объектов негативно воздействуют такие процессы, как [4]:

- нестабильность валютного курса рубля;

- снижение доходов в федеральный бюджет РФ;

- распространение пандемии коронавируса и принятие карантинных мероприятий/ограничений.

Это снижает прогнозы экономического роста, что соответственно влияет на хозяйствующую и инвестиционную активность предпринимательских субъектов, а также на покупательные способности населения.

С другой стороны, условия рынка недвижимости в период пандемии 2020 г. характеризуются принятием Правительством РФ стимулирующих мер, способствующих развитию ипотеки как главного способа проведения сделок по покупке/продаже объектов недвижимости.

Так, в период с 2019 по 2020 г. уровень процентных ставок на ипотечное жилищное кредитование рынка новостроек снизился с 10,23 до 6,09\%, продемонстрировав рекордный минимум.

В период с 2019 по 2020 г. уровень процентных ставок на ипотечное жилищное кредитование рынка вторичной жилой недвижимости снизился с 10,8 до $8,46 \%{ }^{1}$.

1 Итоги развития рынков ипотеки. URL: https://дом.pф/upload/iblock/d67/ d67c06f1da33136566c346f2dbb24128.pdf (дата обращения: 29.03.2021). Текст: электронный. 
Д. Д. Цыренов, Д. О. Жапова, М. Б. Цыденов. Рынок жилой недвижимости в Дальневосточном федеральном округе: тенденции и перспективы

Причинами такого рекордного снижения уровня процентных ставок на ипотечное жилищное кредитование является государственная программа Правительства РФ, после завершения которой процентные ставки на новостройки могут вернуться к обратному значению - $8 \%$ годовых.

По нашему мнению, активное участие государства в антикризисном управлении рынка ипотечного кредитования в России позволяет нивелировать негативное воздействие проблем, возникающих в рамках кризиса рынка недвижимости в условиях пандемии коронавируса.

Следующей тенденцией развития рынка жилой недвижимости в ДВФО выступает рекордный рост выдачи ипотечных кредитов на первичном рынке жилья в сравнении с другими регионами Российской Федерации.

Так, с 1 декабря 2019 г. в ДВФО действует программа «Дальневосточная ипотека», которая направлена на улучшение жилищных условий граждан и развитие строительного сектора. Программа позволяет оформить кредит (не более 6 млн р.) по ставке $2 \%$ молодым семьям (не старше 35 лет) ${ }^{2}$.

В конечном итоге за 2019 г. и 2020 г. динамика роста ипотечного кредитования рынка жилья по регионам России выглядит следующим образом (рисунок 2).

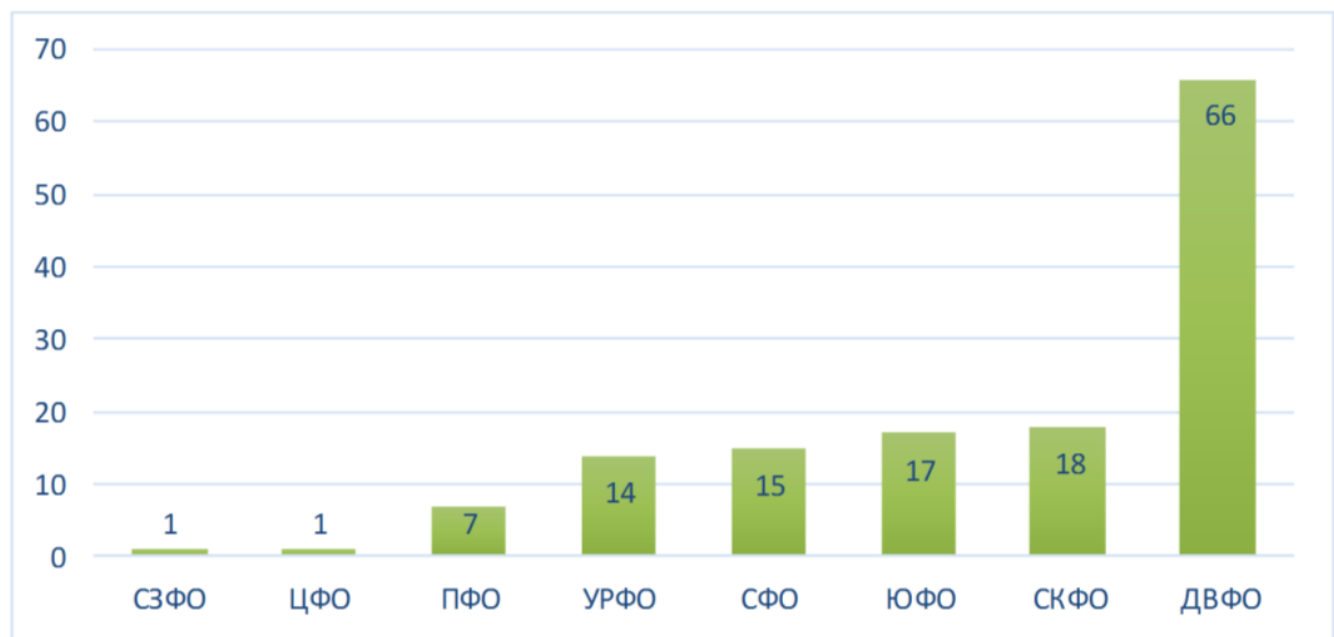

Рис. 2. Динамика роста ипотечного кредитования рынка жилья в 2019-2020 гг. по регионам России, в ${ }^{3}$

Как видно из рисунка 2, можно заключить следующее: региональная поддержка рынка жилой недвижимости в ДВФО наиболее эффективна с точки зрения роста ипотеки для населения, поскольку программа с льготными 2\% годовых - это конкурентное преимущество, позволяющее увеличивать портфель

1 Обзор рынков жилья, жилищного строительства и ипотеки. URL: https://дом.pф/upload/iblock/e8b/e8b089e88ad8d89e195114ac8f554d7b.pdf (дата обращения: 29.03.2021). Текст: электронный.

2 Итоги развития рынков ипотеки. URL: https://дом.pф/upload/iblock/e8b/e8b089e88 ad8d89e195114ac8f554d7b.pdf (дата обращения: 29.03.2021). Текст: электронный.

${ }^{3}$ Там же. 
ипотеки на $66 \%$, что в разы выше, чем у других региональных субъектов Российской Федерации.

В рамках дальнейшего развития рынка жилой недвижимости в Дальневосточном федеральном округе можно выделить две основные версии:

1. Положительная версия, характеристика которой заключается в том, что будет наблюдаться как рост объема строительства жилой недвижимости, выдачи ипотечного кредитования, так и рост цен. При этом последняя тенденция будет связана с увеличением размера личных доходов населения региона.

2. Негативная версия, характеристика которой заключается в том, что государственная поддержка программы льготного ипотечного кредитования остановится, что приведет к «схлопыванию пузыря» рынка ипотечных ценных бумаг ${ }^{1}$. При этом изъяны рынка жилой недвижимости могут проявиться из-за постпандемического периода, когда спад макроэкономических показателей приведет к ухудшению качества жизни населения, что снизит объемы спроса на объекты жилой недвижимости.

В заключение можно прийти к выводу, что основными тенденциями развития рынка жилой недвижимости в ДВФО выступают увеличение масштабов ипотечного жилищного кредитования и рост цен. Такие характеристики означают увеличение капитализации рынка жилой недвижимости и повышение совокупного спроса и предложения. В итоге такие сигналы характеризуют положительные перспективы дальнейшего развития рынка жилой недвижимости в регионе.

\section{Литература}

1. Клочкова Е. Н., Толстякова М. А. Рынок жилой недвижимости: тенденции и перспективы // Статистика и экономика. 2019. № 3. С. 24-33. Текст: непосредственный.

2. Айзинова И. М. Ипотечное кредитование как инструмент жилищной политики // Научные труды: Институт народнохозяйственного прогнозирования РАН. 2017. № 15. С. 489-510. Текст: непосредственный.

3. Аракелян Н. Ф., Караваева Ю. С. Состояние российской системы ипотечного кредитования // Вестник евразийской науки. 2018. № 2. С. 1-9. Текст: непосредственный.

4. Берлизев Б.М. Анализ рынка жилищно-ипотечного кредитования в России // Актуальные проблемы менеджмента, экономики и экономической безопасности. 2020. С. 5459. Текст: непосредственный.

5. Любовцева Е. Г., Савдерова А. Ф. Перспективные направления развития кредитования населения // Вестник евразийской науки. 2018. № 4. С. 1-8. Текст: непосредственный.

6. Караваева Ю. С. Современный рынок ипотечного кредитования и проблемы его развития // Вестник НГИЭИ. 2018. № 2(81). С. 133-145. Текст: непосредственный.

Статья поступила в редакиию 30.03.2021; одобрена после рецензирования 28.04.2021; принята к публикации 28.04.2021.

\footnotetext{
${ }^{1}$ Ценовой пузырь: что будет с рынком жилья из-за продления льготной ипотеки. URL: https://realty.rbc.ru/news/5f918d599a7947cf14a6e24b (дата обращения: 29.03.2021). Текст: электронный.
} 
Д. Д. Цыренов, Д. О. Жапова, М. Б. Цыденов. Рынок жилой недвижимости в Дальневосточном федеральном округе: тенденции и перспективы

\title{
RESIDENTIAL REAL ESTATE MARKET IN THE FAR EASTERN FEDERAL DISTRICT: TRENDS AND PROSPECTS
}

\author{
Dashi D. Tsyrenov \\ dashi555@mail.ru \\ Diana O. Zhapova \\ Student \\ zhapovadiana@gmail.com \\ Maidari B. Tsydenov \\ Student \\ tmaidari@mail.ru \\ Dorzhi Banzarov Buryat State University \\ 24a Smolina St., Ulan-Ude 670000, Russia
}

Abstract. The article analyzes the main trends and prospects for the development of residential real estate market in the Far Eastern Federal District (FEFD). The relevance of the study is determined by several factors: firstly, a tendency of increasing the volume of Russian residential real estate market, which is associated with the socio-economic development of the state; secondly, the crisis caused by the COVID-19 pandemic, because of which many processes of housing market development face a number of restrictions. In the article it is considered the development of residential real estate market in the Far Eastern Federal District, and its main trends. We have identified the factors that contribute to its development or, conversely, create obstacles, as well as the main prospects for the further development of residential real estate market in the Far Eastern Federal District. The main trends in the development of residential real estate market in the Far Eastern Federal District are an increase in the scale of mortgage lending, and advance in prices followed by the value creation of residential real estate market and growth of composite demand and supply.

Keywords: real estate market, residential real estate market, residential real estate, mortgaging, mortgage credit lending, mortgage loan, real estate, Far Eastern Federal District, the Far Eastern Federal District, housing market

For citation

Tsyrenov D. D., Zhapova D. O., Tsydenov M. B. Residential Real Estate Market in the Far Eastern Federal District: Trends and Prospects. Bulletin of Buryat State University. Economy and Management. 2021; 2: 90-95 (In Russ.).

The article was submitted 30.03.2021; approved after reviewing 28.04.2021; accepted for publication 28.04.2021. 